\title{
Optimasi Jumlah Kedatangan KRL Commuter Line untuk Mengatasi Penumpukan Penumpang Jalur Bekasi - Jakarta Kota Menggunakan Simulasi Promodel
}

\section{Optimization Total Arrival Commuter Line Train to Overcome Passenger's Accumulation Bekasi - Jakarta Kota Using Simulation Promodel}

\author{
Mirna Lusiani ${ }^{1 *}$, Steven Chandra ${ }^{2}$ \\ ${ }^{1,2}$ Program Studi Teknik Industri, Universitas Bunda Mulia, Jl. Lodan Raya No. 2 Ancol, Jakarta Utara \\ 14430, Indonesia
}

Diterima: 30 Januari 2018; Direvisi: 4 Februari 2018; Disetujui: 8 Februari 2018

\begin{abstract}
ABSTRAK
Penumpang KRL/Commuter Line yang berjumlah besar selalu bertambah setiap tahunnya akan menimbulkan masalah yang harus dihadapi oleh P.T KAI dengan jumlah penumpang yang sangat besar yang mengakibatkan terjadinya penumpukan penumpang. Total kedatangan penumpang yang terjadi pada sistem nyata adalah 48182 penumpang, dengan waktu sebesar 240 menit (05.00-09.00). Berdasarkan analisis data, diperoleh kesimpulan untuk model sistem Commuter Line Bekasi sampai Jakarta Kota, saat ini mengalami penumpukan penumpang yang kapasitasnya KRL itu sendiri tidak cukup dengan jumlah penumpang yang tidak terangkut adalah 7483 penumpang. Untuk mengatasi Penumpukan penumpang yang terjadi saat ini adalah dengan cara menggunakan skenario usulan yang telah dibuat yaitu menggunakan waktu aktual yaitu 10 menit, dan menambahkan jumlah kereta yang seharusnya 20 kereta menjadi 22 kereta. Hasil model skenario dari hasil simulasi adalah 3034 penumpang yang terangkut. Saran bagi peneliti selanjutnyaagar bisa mengatasi penumpukan penumpang yang lebih sempurna.
\end{abstract}

Kata Kunci: Simulasi, Penumpukan, Antrian

\begin{abstract}
A very large KRL/Commuter Line passenger increases at any time will cause problems to be monitored by P.T KAI with an enormous number of passengers who like to fly passenger accumulation. The total arrival of passengers built upon the system is 48182 passengers, with a time of 240 minutes (05.00-09.00). Based on the data analysis, it can be concluded that the model of Commuter Line Bekasi system to Jakarta Kota is currently stored in the passenger capacity whose KRL capacity itself is not enough with the number of passengers not transported is 7483 passengers. To overcome the current passenger accumulation is to use the scenario that has been made that is using the actual time of 14 minutes and increases the number of trains that should be 20 trains to 22 trains. The simulated scenario model result is 3034 passengers transported. Suggestions for further researchers to cope with a perfect passenger pile.
\end{abstract}

Keywords: Simulation, Accumulation, Queue

\section{PENDAHULUAN}

Daerah Khusus Ibu Kota Jakarta adalah salah satu contoh kota metropolitan yang dikelilingi oleh kota-kota besar seperti Bekasi, Bogor, Tangerang, dan Depok. Komuter adalah seseorang yang melakukan suatu kegiatan bekerja/sekolah/kursus di luar kabupaten/kota tempat tinggal dan secara rutin pergi dan pulang (PP) ke tempat tinggal pada hari yang sama (Badan Pusat Statistik Provinsi DKI, 2015). Pada tahun 2014, jumlah komuter Jabodetabek sebesar 12,67\%

*e-mail: mirna_lusiani@yahoo.com 
atau sebanyak 3.566.178 orang (Badan Pusat Statistik Provinsi DKI, 2015).

Komuter Jabodetabek menggunakan berbagai macam moda transportasi. Berdasarkan moda transportasi, komuter Jabodetabek lebih banyak menggunakan motor, disusul oleh mobil dan kendaraan umum (Badan Pusat Statistik Provinsi DKI, 2015). Kendaraan umum yang dimaksud terdiri dari kereta, Transjakarta/APTB, dan kendaraan jemputan. Dari seluruh komuter di Jabodetabek, Kota Bekasi merupakan kota dengan jumlah komuter terbanyak yang beraktivitas di DKI Jakarta, yaitu 14,80\% (Badan Pusat Statistik Provinsi DKI, 2015). Artinya, sebanyak 526.314 orang yang berangkat dari Bekasi menuju DKI Jakarta setiap hari sepanjang 2014 menggunakan berbagai macam moda transportasi. Oleh karena itu, penelitian ini berfokus pada jalur perjalanan komuter dari Kota Bekasi menuju DKI Jakarta.

Salah satu penyedia jasa MRT adalah P.T KAI Commuter Jabodetabek (KCJ) dengan armada Kereta Rel Listrik (KRL) atau yang bisa disebut dengan Commuter Line yang menjadi andalan banyak pengguna jasa di wilayah Jakarta. Tahun 2016, terhitung 766.000 orang terangkut setiap hari menggunakan Commuter Line (PT. KAI Commuter Jabodetabek, 2016). Penelitian ini membahas perjalanan komuter dari Kota Bekasi menuju DKI Jakarta menggunakan Commuter Line.

Penumpang KRL/Commuter Line yang berjumlah besar selalu bertambah setiap tahun menimbulkan masalah yang harus dihadapi oleh P.T KAI yaitu terjadinya penumpukan penumpang, dan terjadinya keterpaksaan yang dikarenakan tidak ada pilihan lain yang memadai. Penggunaan Commuter Line lebih memudahkan para pekerja, pelajar dan traveller jika dibandingkan dengan moda transportasi lain seperti Transjakarta, Damri dan lain-lain. Selain itu, Commuter Line dapat menempuh jarak yang jauh dengan waktu yang efisien, dapat menghindari macet, dan aman. Masalah yang sering dialami oleh para pengguna KRL adalah padatnya penumpang yang melebihi kapasitas dan pemberitahuan informasi yang kurang tepat. Masalah ini terjadi di setiap waktu, bukan hanya di waktu-waktu tertentu.

Dengan adanya satu jenis rute kereta dapat memengaruhi kepadatan penumpang yang terjadi sebelum bulan Maret 2017. Setelah Maret 2017, sudah terdapat 2 rute yang berbeda dari stasiun Bekasi sampai stasiun Jakarta Kota, yaitu jalur atas yang dimulai dari Stasiun Bekasi - Stasiun Manggarai - Stasiun Juanda - Stasiun Jakarta Kota dan jalur yang lain adalah jalur bawah yang mulai dari Stasiun Bekasi - Stasiun Jatinegara - Stasiun Pasar Senen - Stasiun Kampung Bandan - Stasiun Jakarta Kota. Penelitian ini memberikan usulan agar kapasitas dapat menyesuaikan kebutuhan. Penelitian ini juga membantu PT. KCJ untuk membuat sebuah model simulasi dari sistem nyata berbagai cara/skenario yang telah dibuat untuk meminimalkan penumpukan penumpang.

Simulasi adalah proses sistem nyata dan melakukan sebuah eksperimen dengan model ini dengan tujuan untuk memahami perilaku suatu sistem. Simulasi dapat diterapkan untuk sistem yang kecil maupun besar. Biaya dalam membangun sistem nyata lebih banyak dan simulasi dapat memberikan replika model yang tepat dengan tingkah laku sistem (Sameer, 2014). Adapun yang beranggapan bahwa simulasi sebenarnya dapat dilakukan untuk menjalankan selama periode waktu yang representatif, keuntungan dari model berbasi komputer berdasarkan perhitungan manual yang berada dalam jumlah waktu yang dibutuhkan untuk memproses data simulasi dan simulasi dapat diulang beberapa kali untuk melihat konsistensi hasil (Watkins, 1984).

\section{METODOLOGI}

Tahapan penelitian yang dilakukan adalah sebagai berikut:

a. Tahap I Persiapan.

Pada tahap ini, dilakukan pembahasan terhadap literatur yang berhubungan Dengan penelitian, mengidentifikasi masalah yang ada dan menentukan tujuan dari penelitan ini.

b. Tahap II Pengumpulan Data

Pengumpulan data dilakukan pada tanggal 6-11 Maret 2017 dilakukan pada jam 
sibuk di pagi hari pukul 05.00 - 09.00, melalui observasi langsung, terdapat dua jenis data yang dikumpulkan, yaitu data primer didapatkan melalui pengamatan langsung berupa data jarak tempuh KRL tiap stasiun, waktu henti KRL tiap stasiun dan data sekunder berupa data yang didapatkan langsung dari perusahaan Commuter Line didapatkan data naik turun penumpang.

c. Tahap III Pembuatan Model Simulasi Pengolahan data yang dilakukan untuk menentukan distribusi jumlah kedatangan dan turun penumpang, distribusi waktu tempuh KRL tiap stasiun, dan distribusi waktu henti KRL tiap stasiun. Selanjutnya akan dibantu olef software ProModel, dibuat model simulasi dari stasiun awal yaitu stasiun Bekasi sampai stasiun akhir yaitu stasiun Jakarta Kota.

d. Tahap IV Verifikasi dan Validasi Verifikasi dilakukan dengan cara membandingkan kesesuaian antara process logic dari model simulasi dengan alur proses KRL sistem nyata. Sedangkan validasi dilakukan dengan uji Independent sample t test (uji perbedaan rata-rata $<30$ data) dan uji $\mathrm{F}$ (uji variansi) antara ratarata LOS pasien dan jumlah kedatangan pasien dari hasil running model simulasi dengan pengolahan data historis pasien.

e. Tahap V Analisis

Setelah model simulasi telah dinyatakan terverifikasi dan dinyatakan valid, selanjutnya dilakukan simulasi terhadap beberapa skenario. Kemudian pilih skenario terbaik yang dapat menjawab dan memberikan solusi terhadap permasalahan yang didefinisikan sebelumnya pada tahap persiapan.

f. Tahap VI Penutup

Pada tahap ini, dilakukan penarikan kesimpulan terhadap tujuan dari penelitian.

\subsection{Kapasitas dan Alur Proses KRL}

Commuter Line memiliki kapasitas yang sama yaitu 250 setiap gerbongnya, sedangkan 1 Commuter Line memiliki 12 gerbong dengan demikian total kapasitas
Commuter Line adalah 3000 orang. Jam sibuk kedatangan Pekerja, Pelajar dan traveller pada pagi hari pukul $05.00-10.00$.

KRL/Commuter Line memiiki alur proses:

1. Penumpang datang melalui titik kedatangan Bekasisesuai dengan distribusi waktu antar kedatangan. Kemudia penumpang bergerak dari titik kedatangan menuju lokasi antrian lalu penumpang akan di load sebesar 3000.

2. KRL akan datang dati titik kedatangan KRL dengan distribusi waktu yang telah ditentukan pada arrival. KRL kemudia menuju titik naik lokasi stasiun Bekasi dan stasiun-stasiun selanjutnya untuk mengangkut penumpang.

3. KRL yang telah terisi penumpang bergerak dari titik naik Bekasi menuju titik turun Kranji dengan waktu tempuh berdistribusi normal untuk jalur Bekasi menuju Kranji. Selanjutnya KRL akan sampai pada titik turun Kranjidan menurunkan penumpang sesuai dengan distribusi penumpang yang turun untuk stasiun Kranji. Fungsi yang digunakan unload setelah itu penumpang dari titik turun Kranji akan keluar dari sistem.

4. KRL dari titik turun Kranjiakan di tampung sementara pada lokasi titik sementara Kranji untuk menurunkan jumlah penumpang yang tersisa di dalam KRL dengan menggunakan fungsi unload kapasitas maksimal KRL. Selanjutnya penumpang akan dipindahkan ke titik tampung untuk bergerak menuju titik naik Kranjidengan funsi load kapasitas maksimal. KRL yang berpindah pada titik turun menuju titik sementara dan dari titiksementara menuju titik naik tidak menggunakan waktu atau waktu perpindahan sama dengan 0 karena kondisi nyatanya hanya ada satu titik saja. Lama henti KRL pada saat berada di titik naik Kranji adalah sesuai dengan distribusi waktu henti KRL pada stasiun Kranji yang telah di olah datanya.

5. Proses yang diatas akan berulang pada setiap stasiunnya, namun dengan waktu dan jumlah yang berbeda yaitu sesuai dengan distribusi yang telah diolah pada setiap stasiunnya. Pada stasiun terakhir 
yaitu stasiun Jakarta Kota penumpang yang berada pada titik turun kemudian akan keluar dari sistem (exit).

\subsection{Data Aktual dan Distribusi Data}

Data aktual penumpang yang digunakan merupakan data bulan 6 Maret 2017 sampai 11 Maret 2017, dimana total rata-rata penumpang adalah 8812 penumpang. Pada penelitian ini, dibuat terlebih dahulu model simulasi berdasarkan kondisi sistem nyata menggunakan rata-rata tingkat kedatangan penumpang, yaitu 4591. Selanjutnya data penumpang KRL pada kondisi normal diolah berdasarkan kebutuhan pembuatan model. Hasil pengolahan menunjukkan kedatangan penumpang KRL terbesar adalah Stasiun Bekasi yang mengikuti distribusi normal dengan $\mathrm{N}(1175.68,52.16)$, distribusi waktu tempuh terbesar pada Stasiun Manggarai yang mengikuti distribusi normal dengan $\mathrm{N}(7.58$,
1.170), distribusi waktu henti tiap stasiun terbsar pada Stasiun Manggarai yang mengikuti distribusi normal dengan $\mathrm{N}(57$, 2.104)

\subsection{Model Simulasi dan Batasan Model}

Model simulasi yang dibuat berdasarkan elemen-elemen yang mendekati sistem nyata, dimana terdapat 97 lokasi yaitu 14 titik naik, 14 titik turun, 15 titik kedatangan penumpang, 14 lokasi antrian berupa conveyor, 13 titik tampung, 13 titik sementara. Titik tampung dan titik sementara digunakan untuk menutupi kelemahan ProModel itu sendiri yang tidak dapat membaca sisa penumpang. Selanjutnya 2 entitas yaitu KRL dan penumpang. Lalu terdapat 42 variabel yang digunakan dalam perancangan model simulasi ini. Untuk yang terakhir adalah terdapat 1 kedatangan yaitu KRL.

Tabel 1. Distribusi Waktu

\begin{tabular}{cccc}
\hline No & $\begin{array}{c}\text { Kedatangan Stasiun } \\
\text { Bekasi }\end{array}$ & $\begin{array}{c}\text { Henti KRL Stasiun } \\
\text { Manggarai }\end{array}$ & $\begin{array}{c}\text { Jarak Tempuh Stasiun } \\
\text { Manggarai }\end{array}$ \\
\hline $\mathbf{1}$ & 1139 & 7 & 60 \\
\hline $\mathbf{3}$ & 1154 & 7 & 58 \\
\hline $\mathbf{4}$ & 1235 & 7 & 55 \\
\hline $\mathbf{5}$ & 1221 & 11 & 56 \\
\hline $\mathbf{6}$ & 1222 & 7 & 54 \\
$\mathbf{7}$ & 1230 & 7 & 59 \\
\hline $\mathbf{8}$ & 1137 & 7 & 57 \\
\hline $\mathbf{9}$ & 1121 & 8 & 58 \\
\hline $\mathbf{1 0}$ & 1116 & 7 & 55 \\
\hline $\mathbf{1 1}$ & 1122 & 8 & 58 \\
\hline $\mathbf{1 2}$ & 1133 & 7 & 54 \\
\hline $\mathbf{1 3}$ & 1148 & 7 & 57 \\
\hline $\mathbf{1 4}$ & 1257 & 7 & 59 \\
\hline $\mathbf{1 5}$ & 1233 & 10 & 53 \\
\hline $\mathbf{1 6}$ & 1249 & 7 & 60 \\
\hline $\mathbf{1 7}$ & 1244 & 9 & 57 \\
\hline $\mathbf{1 8}$ & 1138 & 7 & 55 \\
\hline $\mathbf{1 9}$ & 1141 & 7 & 58 \\
\hline $\mathbf{2 0}$ & 1134 & 7 & 55 \\
\hline Total & 1140 & 8 & 57 \\
\hline Rata- & 23514 & 152 & 56.7 \\
rata & 1175.68 & 7.6 & 2.048 \\
\hline St. Dev & & & $\mathrm{N}(56.7,2.048)$ \\
\hline & 52.16 & 1.142 & \\
\hline
\end{tabular}




\subsection{Validasi}

Validasi model simulasi dilakukan dengan uji statistik, $T$ test (menggunakan tingkat keyakinan $95 \%$ atau $p=0,05)$ dan $F$ test, (menggunakan tingkat keyakinan 95\% atau $F=0.05$ ). Model simulasi terlebih dahulu dijalankan dengan run hours $=4$ jam dan dengan replikasi sebanyak 30 kali, kemudian dilakukan pengujian. Uji perbedaan rata-rata $T$-test, yang dilakukan menghasilkan nilai $P$-value $>0.05$, yakni 0.949 menyatakan bahwa tidak terdapat perbedaan antara rata-rata penumpang KRL.

Uji variansi. F-test, yang dilakukan menghasilkan nilai $P$-value $>0.05$, yakni 0.446 , menyatakan bahwa tidak terdapat perbedaan antara variansi penumpang KRL.

Dari hasil pengujian yang dilakukan, maka model simulasi dapat dinyatakan valid karena tidak ditemukan perbedaan, baik dari segi rata-rata maupun variansi, antara hasil simulasi dengan sistem nyata.

\subsection{Skenario Model}

Pada penelitian ini, model simulasi dijalankan terhadap sejumlah skenario yang merupakan kombinasi antara waktu kedatangan KRL dengan jumlah KRL.terdapat 8 skenarioyang memiliki jumlah penumpang yang berbedadan penumpang yang terangkut yang berbeda. 8 skenario merupakan skenario yang terbaik adalah skenario 8 dengan menambah KRL yang sistem nyatanya adalah 20 KRL menjadi 22 KRL, dengan waktu antar kedatangan yaitu 10 menit.

\section{HASIL DAN PEMBAHASAN}

Skenario dijalankan pada model simulasi yang telah dibuat dengan replikasi 30 kali. Hasil simulasi menunjukkan bahwa dengan ditambahnya jumlah KRL dan menggunakan waktu antar kedatangan KRL pada sistem nyata dapat mengurangi penumpukan penumpang pada sistem nyata.

Adapun terdapat beberapa skenario yang terpilih untuk mengoptimalkan penumpukan penumpang, antara lain:

1. Skenario 1 total jumlah penumpang 48198 dengan menggunakan KRL sama seperti sistem nyata yaitu $20 \mathrm{KRL}$, dan waktu antar kedatangan sistem nyata 10 menit berubah menjadi 12 menit dengan total penumpang yang terangkut adalah 16 penumpang.

2. Skenario 2 total jumlah penumpang 48204 dengan menggunakan KRL sama seperti sistem nyata yaitu $20 \mathrm{KRL}$, dan waktu antar kedatangan sama seperti sistem nyata yaitu 10 menit dengan total penumpang yang terangkut adalah 22 penumpang.

3. Skenario 3 total jumlah penumpang 48624 dengan menggunakan $21 \mathrm{KRL}$ dan waktu antar kedatangan sistem nyata 10 menit berubah menjadi 14 menit dengan total penumpang yang terangkut adalah 442 penumpang.

4. Skenario 4 total jumlah penumpang 48836 dengan menggunakan $21 \mathrm{KRL}$ dan waktu antar kedatangan sistem nyata 10 menit berubah menjadi 12 menit dengan total penumpang yang terangkut adalah 654 penumpang.

5. Skenario 5 total jumlah penumpang 49433 dengan menggunakan $21 \mathrm{KRL}$ dan waktu antar kedatangan tetap seperti sistem nyata yaitu 10 menit dengan total penumpang yang terangkut adalah 1251 penumpang.

6. Skenario 6 total jumlah penumpang 50127 dengan menggunakan $22 \mathrm{KRL}$ dan waktu antar kedatangan sistem nyata 10 menit berubah menjadi 14 menit dengan total penumpang yang terangkut adalah 1945 penumpang.,

7. Skenario 7 total jumlah penumpang 50224 dengan menggunakan $22 \mathrm{KRL}$ dan waktu antar kedatangan sistem nyata 10 menit berubah menjadi 12 menit dengan total penumpang yang terangkut adalah 2026 penumpang.

8. Skenario 8 total jumlah penumpang 51126 dengan menggunakan 22 KRL dan waktu antar kedatangan sama seperti sistem nyata yaitu 10 menit dengan total penumpang yang terangkut adalah 3034 penumpang 
Tabel 2. Skenario

\begin{tabular}{clcc}
\hline $\begin{array}{c}\text { Skenario } \\
\text { Pkenario } \\
\mathbf{1}\end{array}$ & $\begin{array}{l}\text { 20 KRL dengan waktu antar kedatangan } \\
12 \mathrm{menit}\end{array}$ & $\begin{array}{c}\text { Penumpang } \\
\text { Terangkut }\end{array}$ & $\begin{array}{c}\text { Jumlah } \\
\text { Penumpang }\end{array}$ \\
\hline $\begin{array}{c}\text { Skenario } \\
\mathbf{2}\end{array}$ & $\begin{array}{l}20 \mathrm{KRL} \text { dengan waktu antar kedatangan } \\
10 \mathrm{menit}\end{array}$ & 22 & 48198 \\
\hline $\begin{array}{c}\text { Skenario } \\
\mathbf{3}\end{array}$ & $\begin{array}{l}21 \mathrm{KRL} \text { dengan waktu antar kedatangan } \\
14 \mathrm{menit}\end{array}$ & 442 & 48204 \\
\hline $\begin{array}{c}\text { Skenario } \\
\mathbf{4}\end{array}$ & $\begin{array}{l}21 \mathrm{KRL} \text { dengan waktu antar kedatangan } \\
12 \text { menit }\end{array}$ & 654 & 48624 \\
\hline $\begin{array}{c}\text { Skenario } \\
\mathbf{5}\end{array}$ & $\begin{array}{l}21 \mathrm{KRL} \text { dengan waktu antar kedatangan } \\
10 \text { menit }\end{array}$ & 1251 & 48836 \\
\hline $\begin{array}{c}\text { Skenario } \\
\mathbf{6}\end{array}$ & $\begin{array}{l}22 \mathrm{KRL} \text { dengan waktu antar kedatangan } \\
14 \text { menit }\end{array}$ & 1945 & 49433 \\
\hline $\begin{array}{c}\text { Skenario } \\
\mathbf{7}\end{array}$ & $\begin{array}{l}22 \mathrm{KRL} \text { dengan waktu antar kedatangan } \\
12 \text { menit }\end{array}$ & 2026 & 50127 \\
\hline $\begin{array}{c}\text { Skenario } \\
\mathbf{8}\end{array}$ & $\begin{array}{l}22 \mathrm{KRL} \text { dengan waktu antar kedatangan } \\
10 \text { menit }\end{array}$ & 3034 & 50224 \\
\hline
\end{tabular}

\section{KESIMPULAN}

Untuk model sistem Commuter Line Bekasi sampai Jakarta Kotayang terjadi saat ini mengalami penumpukan yang kapasitas KRL itu sendiri tidak memadai untuk mengangkut penumpang pada tahun 2017 ini, dengan jumlah penumpang yang tidak terangkut adalah 7483 penumpang. Telah dibuatnya berbagai usulan untuk mengatasi penumpukan penumpang agar menjadi lebih baik, yaitu sebagai berikut:

1. Skenario 1 total jumlah penumpang 48198 dengan menggunakan KRL sama seperti sistem nyata yaitu $20 \mathrm{KRL}$, dan waktu antar kedatangan sistem nyata 10 menit berubah menjadi 12 menit dengan total penumpang yang terangkut adalah 16 penumpang.

2. Skenario 2 total jumlah penumpang 48204 dengan menggunakan KRL sama seperti sistem nyata yaitu $20 \mathrm{KRL}$, dan waktu antar kedatangan sama seperti sistem nyata yaitu 10 menit dengan total penumpang yang terangkut adalah 22 penumpang.

3. Skenario 3 total jumlah penumpang 48624 dengan menggunakan $21 \mathrm{KRL}$ dan waktu antar kedatangan sistem nyata 10 menit berubah menjadi 14 menit dengan total penumpang yang terangkut adalah 442 penumpang.

4. Skenario 4 total jumlah penumpang 48836 dengan menggunakan 21 KRL dan waktu antar kedatangan sistem nyata 10 menit berubah menjadi 12 menit dengan total penumpang yang terangkut adalah 654 penumpang.

5. Skenario 5 total jumlah penumpang 49433 dengan menggunakan $21 \mathrm{KRL}$ dan waktu antar kedatangan tetap seperti sistem nyata yaitu 10 menit dengan total penumpang yang terangkut adalah 1251 penumpang.

6. Skenario 6 total jumlah penumpang 50127 dengan menggunakan $22 \mathrm{KRL}$ dan waktu antar kedatangan sistem nyata 10 menit berubah menjadi 14 menit dengan total penumpang yang terangkut adalah 1945 penumpang.

7. Skenario 7 total jumlah penumpang 50224 dengan menggunakan $22 \mathrm{KRL}$ dan waktu antar kedatangan sistem nyata 10 menit berubah menjadi 12 menit dengan total penumpang yang terangkut adalah 2026 penumpang.

8. Skenario 8 total jumlah penumpang 51126 dengan menggunakan $22 \mathrm{KRL}$ dan waktu antar kedatangan sama seperti sistem nyata yaitu 10 menit dengan total penumpang yang terangkut adalah 3034 penumpang.

Hasil skenario terbaik adalah skenario 8 yaitu dengan cara menambahkan jumlah KRL, dari $20 \mathrm{KRL}$ menjadi $22 \mathrm{KRL}$. Selain itu, waktu antar kedatangan tetap sama seperti sistem nyata yaitu 10 menit dengan 
total penumpang 51216 dan penumpang yang terangkut adalah 3034 .

\section{DAFTAR PUSTAKA}

Badan Pusat Statistik Provinsi DKI (2015) Komuter DKI Jakarta Tahun 2014. Tersedia pada: https://jakarta.bps.go.id/pressrelease/2015/02/20/59/komuter-dki-jakarta-tahun2014.html.

PT. KAI Commuter Jabodetabek (2016) Laporan Tahunan 2016: Towards Excellent Public Service and Beyond. Jakarta.

Sameer, S. S. (2014) "Simulation: Analysis of Single Server Queuing Model," International Journal on Information Theory, 3(3), hal. 47-54. doi: 10.5121/ijit.2014.3305.

Watkins, T. (1984) "Optimising Bank Service Provision: A Simulation Approach," International Journal of Bank Marketing, 2(1), hal. 31-39. doi: 10.1108/eb010733. 